\title{
Research of Evaluation on Cultivated Land Fertility in Xinjiang Desert Oasis Based on GIS Technology Taking No. 22 State Farm as the Example*
}

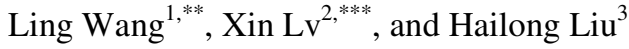 \\ ${ }^{1}$ Department of Geography, Teachers College, Shihezi University, Shihezi, \\ Xinjiang Province, P. R. China 832003 \\ rain_ling@163.com \\ ${ }^{2}$ Key Laboratory of Oasis Ecological Agriculture of Xinjiang Production \& Construction \\ Corps(XPCC), Shihezi University, Shihezi, Xinjiang Province, P. R. China 832003 \\ Tel.: +86-13909931721 \\ 1xshz@126.com \\ ${ }^{3}$ College of Water Conservancy Construction Engineering, Shihezi University, Shihezi, \\ Xinjiang Province, P. R. China 832003
}

\begin{abstract}
This paper, with No.22 State Farm, Agricultural Division No.2, XPCC as the example and under support of GIS, takes cultivated land plot as the evaluation unit and chooses 13 influence factors from five aspects of nutrient of cultivation layer, physical and chemical properties of cultivation layer, soil management, climate conditions and obstacle factor to establish desert oasis cultivated land fertility evaluation system and model. On the basis of a great quantity of information related to cultivated land fertility through field sampling and laboratory analysis, and supported by GIS, the papers takes advantages of mathematics method and mathematical model such as hierarchical analysis process and fuzzy comprehensive evaluation process to realize automatic and quantitative evaluation on cultivated land fertility, analyze area statistics and distribution characteristics of cultivated land fertility at different levels and main attribute of cultivated land at various classes in State Farm No.22, and give analysis of the space distribution. Results show that cultivated land in state farm No.22 can be divided into six classes, of which Class 1 Land IFI (integrated fertility index) is $0.74 \sim 1.00$, area $3788.11 \mathrm{hm} 2$, accounting for $7.67 \%$ of the total area; Class 2 - Class 6 Land for $36.45 \%, 43.47 \%, 12.32 \%, 0.089 \%$ and $0.0001 \%$ of the total area respectively. Research results are of significance in guiding local cultivated land quality management and promoting construction of new rural area.
\end{abstract}

Keywords: Geographical information system (GIS), Cultivated land fertility, Desert oasis.

\footnotetext{
* Foundation project: the Foundation of Xinjiang Uygur Autonomous Region for Philosophy and Social Sciences (07JYB027).

** Primary author.

**** Corresponding author.
}

D. Li, Y. Liu, and Y. Chen (Eds.): CCTA 2010, Part II, IFIP AICT 345, pp. $290-299.2011$.

(C) IFIP International Federation for Information Processing 2011 


\section{Introduction}

Cultivated land is the foundation of agriculture and one of important resources guaranteeing sustainable development of the society and national economy. Evaluation on cultivated land fertility means a process assessing production potential and suitability of cultivated land for better utilization of land, so as to reveal bio-productivity capacity and potential productivity[1]. For recent decades, several surveys of land resources and general surveys of soil have been made in China. However, with social and economic development, great changes have taken place in quality and quantity of land utilizations and agricultural land(particularly cultivated land), existing data have become outdated and traditional survey method backward, failing to meet the need of modern agricultural production. GIS technology, however, can realize effective management of cultivated land resources with space characteristics. In recent years, with application of $3 \mathrm{~S}$ technology, management and use of cultivated land resources have become more reasonable. For example, Zhang Haitao and others, by using GIS, introduced hierarchical analysis principle and method into evaluation on cultivated land fertility, for determining weight of involved factors, quickly and accurately completing comprehensive evaluation on natural fertility of cultivated land in Houhu Area in Jianghan Plain [2]; Zhou Hongyi and others, with SORER database as the foundation, made evaluation on fertility class of 53 cultivated land units in the typical area (Pengzhou) in upstream Yangtz River [3]; Wang Ruiyan and others took Qingzhou, Shandong Province as the test area and comprehensively used hierarchical cluster method, hierarchical analysis process, fuzzy evaluation method and mathematical model, realizing automatic and quantitative evaluation on cultivated land fertility[4]; Lin Bishan and others took soil species as the unit and adopted limiting factors method and the inductive method to made systematic analysis and appraisal of cultivated land fertility factors and evaluation on cultivated land (soil species ) Ilk force class [5]; He Yurong and others used soil quality coefficient to make evaluation on cultivated land fertility of Chuanjiang River Basin and several typical ecological agricultural zones in the surrounding area, to direct ecological environment construction and agricultural structure adjustment [6]; Liu Youzhao and others, taking Pizhou City, Jiangsu Province as the study-covered area and under support of GIS, made research of evaluation on cultivated land fertility, realizing automatic cultivated land classification and improving results' scientificalness [7]. Therefore, the scientific research and practice using GIS technology to carry out cultivated land fertility survey and quality evaluation, on the one hand, can prepare information reserve for establishment of China's soil fertility information system and precision agriculture system, and help realize global soil information exchange and sharing; on the other hand, will be of great theoretical and practice significance in sounding out about what China has got in soil resources, reasonably utilizing and scientifically administrating land resources, promoting sustained, steady and concerted development of China in population, resources, environment, society and economy[8]. This paper mainly takes State Farm No.22, Agricultural Division No.2 as the example to analyze its cultivated land fertility situations, so as to make contributions to high quality and high yield of grain and economic crops in the Regiment. 


\section{General Description of the Study-Covered Area}

The State Farm No.22 in Yanqi, Ba-Prefecture, Xinjiang, located at the hinterland of Eurasian Continent and southern foot of Tianshan Mountains, with Kaidu River passing through the center and geographical position $86^{\circ} 30^{\prime} \mathrm{E}$ and $42^{\circ} 09^{\prime} \mathrm{N}$, enjoys typical continental North Temperate Zone cold climate, with annual accumulated temperature of $3379^{\circ} \mathrm{C}$, annual average sunshine of 2973 hours, annual precipitation of $93.7 \mathrm{~mm}$, annual average temperature of $7.9^{\circ} \mathrm{C}$, extremely highest temperature of $37.7^{\circ} \mathrm{C}$, extremely lowest temperature of minus $26.5^{\circ} \mathrm{C}$; accumulated temperature $\geq 10^{\circ} \mathrm{C}$ of $3353^{\circ} \mathrm{C}$, frost-free period of 160 180. The Regiment neighbors Bosteng Lake in the east, is encircled by mountains in the south, borders Hular Mountain in the west and is against Tianshan Mountains in the north, making a typical basin area. The Regiment has a square topography, higher in the north and lower in the south, with slope of $1 / 1000$ and altitude of $1057 \mathrm{~m}$. The Regiment has land area of 0.0668 million $\mathrm{hm}^{2}$. Of which cultivated land area is $9530 \mathrm{hm}^{2}$; mountain meadow area is $50,000 \mathrm{hm}^{2}$; forest and fruits area $2467 \mathrm{hm}^{2}$; water area $3133.33 \mathrm{hm}^{2}$; and town-administrated area 3240 $\mathrm{hm}^{2}$. In the Regiment soil is fertile and mainly consists of Quaternary-System sand loam soil, moisture soil, meadow soil, clay, salty soil and humult, etc, belonging to the ancient- past shallow marsh zone of Kaidu River and ancient Bosteng Lake delta. In terms of texture, the soil has sandy loam as the primary part and light loam as the secondary; moderate grain size, organic matter content average of $1.85 \%$, total nitrogen of $0.11 \%$, hydrolyzable nitrogen of $76 \mathrm{mg} / \mathrm{kg}$, rapid available phosphorus of $63 \mathrm{mg} / \mathrm{kg}$, rapid available potassium of $178 \mathrm{mg} / \mathrm{kg}$ and $\mathrm{PH}$ of $7.7 \sim 8.1$, suitable for planting wheat, tomato, pepper, beet, chrysanthemum, oil sunflower, confectionery sunflower, Black Seed Melon and maize, etc as agronomic crop.

\section{Data and Research Method}

\subsection{Data Sources}

Collecting Data. Social and economic statistical data, including social and economic index data of population and land area on the basis of basic unit of administrative division; basic and thematic maps data, including relief map, administrative division map, current land utilization map and soil map, etc.

Field Survey Data. Including topography, landforms, soil parent material, soil layer thickness, cultivation layer texture, current utilization of cultivated land and irrigation and drainage conditions, etc.

Soil Laboratory Analysis Data. According to actual situations of the study-covered area, we decide to arrange points for sampling on the basis of strip field and by the same density (interval). And we give full considerations to utilization of factors of current situations, type of soil species and fertility level, and concurrent consideration to uniformity. Our sampling works are mainly carried out in autumn, with some samplings in summer. On the basis of indoor point arrangement, we select a representative plot in the field, position it with GPS positioner, and adopt "S" method, " $\mathrm{X}$ " method or chessboard method to randomly specify 10 15 sampling points. Each 
sampling point's earth borrow depth and sampling volume should be even and identical, with sampling depth of $0 \sim 20 \mathrm{~cm}$. After full mixing of soil samples, reserve sample by quartering, with $1.5 \mathrm{~kg}$ for key point and $1 \mathrm{~kg}$ for common point. In the State Farm No.22 total 917 soil samples have been collected.

Soil sample analysis and determination items consist of: organic matter, alkalihydrolyzable nitrogen, rapid available phosphorus, rapid available potassium, effective zinc, effective iron, effective manganese, effective copper, salt content and $\mathrm{pH}$ value. Analysis method is subject to the Technical Regulations for National Cultivated Land Fertility Survey and Quality Evaluation.

\subsection{Cultivated Land Fertility Evaluation Method}

This paper, by using geographical information system software ArcGIS and establishing the basic database for State Farm No.22's cultivated land fertility evaluation, comprehensively analyzes factors influencing the State Farm No.22's cultivated land fertility, so as to establish the State Farm No.22's cultivated land fertility evaluation system and model.

Determination of Evaluation Unit. Evaluation unit is the basic space unit for carrying out cultivated land class appraisal and division. The unit has uniform internal quality but big difference between units. Unit division needs comprehensive considerations of natural factors and social and economic factors. According to specific situations of the study-covered area, all sampling points in the State Farm No.22 are divided into evaluation units by strip field.

Determination of Evaluation Index and Its Weight. The substance of cultivated land fertility evaluation is the evaluation on how natural elements such as topography and soil limit growth of local major agronomic crops. Cultivated land fertility evaluation factors consist of climate, topography, soil, vegetation, hydrologic and hydrogeological factors and social and economic factors.

Many factors can influence cultivated land quality, involving various aspects of natural ecological conditions and social, economic and regional conditions. Our research, on the principle of stability, leading, comprehensiveness, difference, quantitation and reality, by referring to the index system of the "National Cultivated Land Fertility Survey and Quality Evaluation" by the Ministry of Agriculture, considering characteristics of the cultivated land resources in Agricultural Division No.2 and following the principle of availability, difference, importance, stability and combination of qualitative and quantitative indexes, selects five standard levels (nutrient of cultivation layer, cultivation layer's physical and chemical properties, soil management, climate conditions and obstacle factor), and 13 indexes (texture, $\mathrm{PH}$, organic matter, alkali-hydrolyzable nitrogen, rapid available phosphorus, rapid available potassium, effective zinc, effective copper, effective iron, effective manganese, accumulated temperature, irrigation guarantee rate and salt content) from the national cultivated land fertility survey and quality evaluation index system, to establish Agricultural Division No.2's cultivated land fertility evaluation index system, which is arranged in manner of target level (A), standard level (B) and index level (C) (See Table 1).

Our research is carried out according to actual situations of the cultivated land soil in Agricultural Division No.2 and on the basis of opinions from relevant experts and 
technicians with practice experience. And weight of every factor is determined as shown in Table 1 according to actual situations of cultivated land soil in the Division and to influence of various factors, and by using hierarchical analysis process and fuzzy comprehensive evaluation process (See Table 1).

Table 1. Cultivated Land Fertility Evaluation Factor and Weight of the State Farm No.22, Agricultural Division No.2

\begin{tabular}{|c|c|c|c|}
\hline Target Level A & \multicolumn{3}{|c|}{ Cultivated Land Fertility } \\
\hline Standard Level B & Index Level C & Single Factor Weight & Combined Weight \\
\hline Nutrient of cultivation layer & & 0.3819 & \\
\hline $\begin{array}{l}\text { Cultivation layer's physical and chemical } \\
\text { properties }\end{array}$ & & 0.1732 & \\
\hline Soil management & & 0.1681 & \\
\hline Climate conditions & & 0.1432 & \\
\hline Obstacle factor & & 0.1336 & \\
\hline \multirow[t]{8}{*}{ Nutrient of cultivation layer } & Organic matter & 0.1788 & 0.0683 \\
\hline & Alkalihydr-olyzable nitrogen & 0.2124 & 0.0811 \\
\hline & Rapid available phosphorus & 0.1584 & 0.0605 \\
\hline & Rapid available potassium & 0.1057 & 0.0404 \\
\hline & Effective copper & 0.0783 & 0.0299 \\
\hline & Effective iron & 0.0915 & 0.0349 \\
\hline & Effective zinc & 0.0932 & 0.0356 \\
\hline & Effective manganese & 0.0817 & 0.0312 \\
\hline \multirow[t]{2}{*}{$\begin{array}{l}\text { Cultivation layer's physical and chemical } \\
\text { properties }\end{array}$} & $\mathrm{PH}$ value & 0.4132 & 0.0716 \\
\hline & Texture & 0.5868 & 0.1016 \\
\hline Soil management & Irrigation guarantee rate & 1.0000 & 0.1681 \\
\hline Climate conditions & Accumulated temperature & 1.0000 & 0.1432 \\
\hline Obstacle factor & $\begin{array}{lll}\text { Cultivation layer's salt } \\
\text { content }\end{array}$ & 1.0000 & 0.1336 \\
\hline
\end{tabular}

Quantizing Treatment of Evaluation Index. According to land fertility and geological survey in Xinjiang, combining specific experiment and expert judgment, we process the quantitative data through combination of fuzzy comprehensive evaluation process and membership function to determine membership function of various evaluation indexes, and introduce evaluation factor value into the membership function, so as to calculate its membership value. For organic matter, alkali-hydrolyzable nitrogen, rapid available phosphorus and rapid available potassium, etc, Type $\mathrm{S}$ membership function is established for qualitative index, the method of grading by multiple experts but taking value on average is adopted.

Quantizing treatment of concept factors. Concept factors such as soil texture, irrigation guarantee rate and accumulated temperature, etc are valuated as follows by adopting experts' grading according to their influence on fertility, namely taking their characteristic value as the membership function (See Table 2.).

Membership function of quantitative index. By using others' research achievements [3], and through induction, feedback, gradual shrinkage and concentration, membership function of the following indexes is established. 
Table 2. Membership Function of Concept Evaluation Index

\begin{tabular}{cllll}
\hline $\begin{array}{c}\text { Accumulated temperature } \\
\text { membership }\end{array}$ & $2000^{\circ} \mathrm{C}$ & $2000 \sim 2200^{\circ} \mathrm{C}$ & $2200 \sim 2400^{\circ} \mathrm{C}$ & $>2400^{\circ} \mathrm{C}$ \\
& 0.21 & 0.45 & 0.65 & 0.85 \\
\hline $\begin{array}{c}\text { Irrigation guarantee rate } \\
\text { membership }\end{array}$ & Fully met & Basically met & Generally met & Not met \\
& 1 & 0.8 & 0.7 & 0.4 \\
\hline Soil texture & loam & clay & sandy loam & sandy soil \\
membership & 0.9 & 0.7 & 0.5 & 0.3 \\
\hline
\end{tabular}

(1) Determining Type S membership function of organic matter, alkali-hydrolyzable nitrogen, rapid available phosphorus and rapid available potassium membership:

$$
f(x)=\left\{\begin{array}{cr}
1.0 & x \geq x_{2} \\
0.9\left(x-x_{1}\right) /\left(x_{2}-x_{1}\right)+0.1 & x_{1} \leq x<X_{2} \\
0.1 & x>x_{1}
\end{array}\right.
$$

(2) Determining Type S membership function of cultivation layer salt content membership:

$$
f(x)=\left\{\begin{array}{cr}
1.0 & x \leq x_{1} \\
0.9\left(x-x_{1}\right) /\left(x_{2}-x_{1}\right)+0.1 & x_{1}<x \leq x_{2} \\
0.1 & x>x_{2}
\end{array}\right.
$$

(3) Determining Type S membership function of effective copper, effective iron, effective zinc, effective manganese membership:

$$
f(x)=\left\{\begin{array}{cc}
1.0 & x \geq x_{2} \\
\left(x-x_{1}\right) /\left(x_{2}-x_{1}\right) & x_{1} \leq x<x_{2} \\
0 & x<x_{1}
\end{array}\right.
$$

Break for value-taking of factors is shown as Table 3.

Table 3. Value Taking of Type S Membership Function's Curve Break

\begin{tabular}{lll}
\hline Break & $\mathrm{X} 1$ & $\mathrm{X} 2$ \\
\hline Organic matter \% & 0.5 & 2.5 \\
Alkalihydrolyzable nitrogen $\mathrm{mg} / \mathrm{kg}$ & 30 & 150 \\
Rapid available phosphorus $\mathrm{mg} / \mathrm{kg}$ & 5 & 25 \\
Rapid available potassium $\mathrm{mg} / \mathrm{kg}$ & 50 & 200 \\
Salt content $\%$ & 0.3 & 2 \\
Effective copper $\mathrm{mg} / \mathrm{kg}$ & 0.5 & 5 \\
Effective iron $\mathrm{mg} / \mathrm{kg}$ & 2.5 & 5 \\
Effective zinc $\mathrm{mg} / \mathrm{kg}$ & 0.5 & 5 \\
Effective manganese $\mathrm{mg} / \mathrm{kg}$ & 1 & 30 \\
\hline
\end{tabular}


(4) Determination of $\mathrm{pH}$ membership

The corresponding membership function for $\mathrm{pH}$ value, etc in soil is a med-type (trapezoid) membership function. The closer the index to certain range, the better the quality of the evaluation object; the farther the index from the range, the poorer the quality of the evaluation object.

$$
f(x)=\left\{\begin{array}{cl}
(x-3.5) / 3 & 3.5<x<6.5 \\
(9.5-x) / 2 & 7.5<x<9 . \\
1 & 6.5 \leq x \leq 7.5 \\
0 & x \leq 3.5 \text { or } X \geq 9.5
\end{array}\right.
$$

Comprehensive Evaluation on Cultivated Land Fertility. Using weighted summation formula to calculate IFI(Integrated Fertility Index) reflecting cultivated land fertility situations. The formula is:

$$
\mathrm{IFI}=\sum \mathrm{Wi} \times \mathrm{Ni} .
$$

Where, Ni and Wi respectively mean membership value and weight coefficient of No. i fertility index.

\section{Evaluation Results and the Analysis}

\subsection{Quantity of Cultivated Land of Various Classes}

According to the above-mentioned cultivated land fertility evaluation method to calculate IFI of cultivated land fertility in State Farm No.22, Agricultural Division No.2. Using equidistance method to divide IFI into six classes (See Table 4.) ; calculate area of plot at various levels and the proportion (Table 5.).

From Table 5. it can be found that the cultivated land in State Farm No.22's $7486.67 \mathrm{hm}^{2}$ basic farmland can be divided into six classes, of which Class 1 Land has IFI(integrated fertility) of $0.74 \sim 1.00$ and area of $378.11 \mathrm{hm}^{2}$, accounting for

Table 4. Division of Agricultural Division No.2's Cultivated Land Fertility

\begin{tabular}{lllllll}
\hline IFI & $0.74 \sim$ & $0.68 \sim$ & $0.63 \sim$ & $0.57 \sim$ & $0.51 \sim$ & $0 \sim$ \\
& 1.00 & 0.73 & 0.67 & 0.62 & 0.56 & 0.51 \\
\hline \multirow{2}{*}{ Class } & Class & Class & Class 3 & Class & Class 5 \\
& 1 & 2 & & 4 & 6 \\
\hline
\end{tabular}

Table 5. Class of Cultivated Land Fertility in State Farm No.22, Agricultural Division No.2

\begin{tabular}{lccc}
\hline Unit & Fertility Class & $\begin{array}{c}\text { Area } \\
\left(\mathrm{hm}^{2}\right)\end{array}$ & Proportion \% \\
\hline State Farm No.22 & Class 1 Land & 378.11 & 7.67 \\
& Class 2 Land & 2566.03 & 36.45 \\
& Class 3 Land & 998.71 & 43.47 \\
& Class 4 Land & 1836.09 & 12.32 \\
& Class 5 Land & 1587.08 & 0.089 \\
& Class 6 Land & 119.21 & 0.001 \\
\hline
\end{tabular}


$7.67 \%$ of the total area ; Class 2 Land has IFI of $0.68 \sim 0.73$ and area of $2566.03 \mathrm{hm}^{2}$, accounting for $36.45 \%$; Class 3 Land has IFI of $0.63 \sim 0.67$ and area of $998.71 \mathrm{hm}^{2}$, accounting for 43.47\%; Class 4 Land has IFI of $0.57 \sim 0.62$ and area of 1836.09 $\mathrm{hm}^{2}$, accounting for $12.32 \%$; Class 5 Land has IFI of $0.51 \sim 0.56$ and area of 1587.08 $\mathrm{hm}^{2}$, accounting for $0.089 \%$; Class 6 Land has IFI of $0 \sim 0.51$ and area of $119.21 \mathrm{hm}^{2}$, accounting for $0.0001 \%$.

\subsection{Space Distribution of Cultivated Land at Various Levels}

With support of GIS software ArcGIS 9.2, on the basis of evaluation unit map and according to cultivated land fertility evaluation of the units, same-class and neighboring units are merged to get polygon of cultivated land fertility classes (See Fig. 1).

In State Farm No.22, Agricultural Division No.2, Class 1 Land, within $10 \%$ of the total, is mainly distributed in Company 3, Company 6, Company 7, Company 8 and Company 9. The Class 1 Land belongs to high/stable-yield field, characterized by highest fertility, flat land, assured irrigation andconcerted water and air, where high yield is common for crops. In the Class 1 Land, soil has good arability, long cultivation period, good permeability and irrigation and quick fertilizer effect. However, attentions should be paid to application of more organic fertilizer and phosphorus/potassium fertilizers to prevent fertility from decreasing.

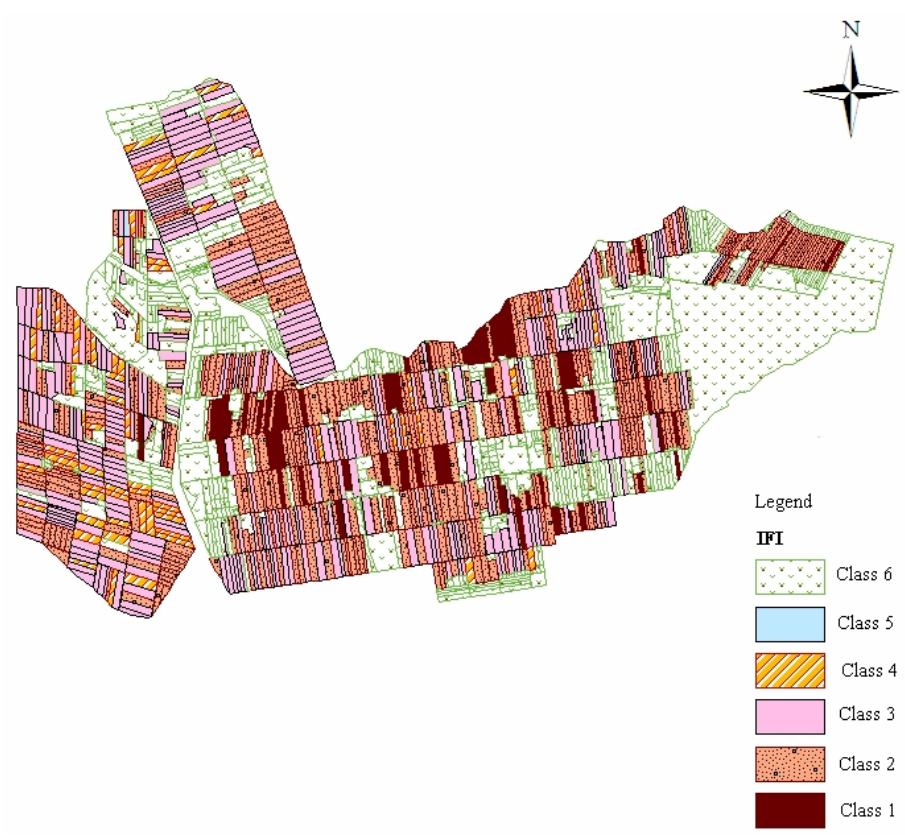

Fig. 1. Cultivated Land Fertility Class of State Farm No.22, Agricultural Division No.2

Class 2 Land accounts for about $35 \%$ of the total, and is distributed in all companies, with the most in Company 1 and the least in Company 2; Class 2 Land boasts higher content of alkali-hydrolyzable nitrogen, rapid available phosphorus, effective 
iron, effective manganese and effective copper, but lower content of organic matter and effective zinc that average of other classes, and soil mainly consisting of loam and sandy loam. In the project area Class 2 Land is characterized by high fertility, flat land, basically-matched irrigation system, concerted water and air, good arability and high nutrient content.

Class 3 Land accounts for up to $43.47 \%$, the highest proportion, and is distributed evenly, with the most in Company 1 and the least in Company 10. Class 3 Land has high content of organic matter and rapid available potassium, alkali-hydrolyzable nitrogen, low content of rapid available phosphorus, and soil mainly consisting of sandy loam and little loam. In the area utilization of soil under Class 3 Land is limited to certain extent, soil's physical property is poor, and irrigation conditions are common, making crop subject to selection. In production, some improvement tests are needed to guarantee yield. The soil here has nutrient under med. level or short partially, needing more organic fertilizer and deepened mature cultivation layer to improve overall growth in soil.

Class 4 Land is mainly distributed in Company 12, Company 13, Company 14 and Company 15. Class 4 Land boasts high organic matter and effective zinc content but low effective iron content, and soil mainly consists of sandy loam. Class 4 Land in the project area is more selective to agronomic crop and poor in soil quality and has considerable part of low-yield field as obstacle level. Class 4 Land has soil characterized by short arable period, hard control, poor overall quality (influencing germination), poor permeability, physical performance and ability against floodwater and drought.

Proportion of Class 5 Land is slightly higher than that of Class 6 Land, very little compared with other classes and only in Company 14. Class 5 Land has average content of rapid available phosphorus and effective zinc the highest, and of other factors the lowest, compared with the average in other classes respectively. Its soil consists of sandy soil and sandy loam. Class 5 Land mainly belongs to low-yield field, basically has obstacle level and is badly limited for agricultural production and more selective to agronomic crop. The soil is poor in quality, fertility, physical performance and permeability. Soil in Class 5 Land should be applied with more organic fertilizer and supported with phosphorus potassium fertilizer.

There is only a plot of Class 6 Land. Class 6 Land is characterized by obviously lower organic matter content and lower content of nutrient factors than those in land of other classes. Its soil mainly consists of sandy soil. Class 6 Land basically belongs to low-yield field, and the soil has poor fertility and physical performance. Yield of crop from the land is very low. Overall content of nutrients is not low, but difference of nutrients is higher, meaning uneven distribution of nutrients. Meanwhile, main limiting factor of Class 6 Land lies in the soil's site conditions and obstacle factor, and the Land needs long-term comprehensive treatment and improvement.

\section{Conclusion}

(1) From the above-mentioned researches it can be found that using GIS technology can quickly and effectively make quantitative and scientific evaluation on cultivated land fertility and the space distribution, saving time, work and effort compared with traditional evaluation method. 
(2) Application of hierarchical analysis process and fuzzy comprehensive evaluation method in cultivated land fertility evaluation can to certain extent reduce influence of subjective factors from evaluator, better reflect fertility difference of cultivated land and improve precision of cultivated land fertility evaluation results.

(3) Using cultivated land plot as evaluation unit means clear space boundary and relationship of administrative subordination, accurate area, identical landforms type and soil type, and basically same utilization mode and cultivation method, making evaluation results more comprehensive and objective and implemented more directly in practice.

(4) The results of evaluation on the basis of cultivated land fertility index of State Farm No.22, Agricultural Division No.2 are in line with actual conditions very much, and have very high guiding significance and practical value.

Acknowledgments. Funding for this research was provided by the Social Science Fund program. The first authors are grateful to Dr. Xin Lv for his insightful comments on this manuscript. We wish to thank Dr. Hailong Liu for his help in organizing the data. The authors also appreciate other members of the Research on the Social Science Fund Project for their assistance.

\section{References}

1. Lu, M., He, L., Wu, S.: GIS-based Research of Evaluation on Cultivated Land Fertility in Central China Hilly Area. Transactions of the Chinese Society of Agricultural Engineering 22(8), 96-101 (2006) (in Chinese)

2. Zhang, H., Zhou, Y., Wang, S.: Comprehensive Evaluation on Natural Fertility of Cultivated Land in Houhu Area, Jianghan Plain by Using GIS, RS Data and Hierarchical Analysis Process. Transactions of the Chinese Society of Agricultural Engineering 19(2), 219-223 (2003) (in Chinese)

3. Wang, R., Zhao, G., Li, T.: GIS-supported Evaluation on Cultivated Land Fertility Class. Transactions of the Chinese Society of Agricultural Engineering 20(1), 307-310 (2004) (in Chinese)

4. Lin, B., Tang, J., Zhang, M.: Research and Evaluation on Cultivated Land Fertility Class in Guangdong. Ecological Environment 14(1), 145-149 (2005) (in Chinese)

5. He, Y., Zhou, H., Zhang, B.: Cultivated Land Fertility and Agricultural Structure Adjustment in Typical Area of Upstream Yangtz River - Taking Chuanjiang River Basin and its Surrounding Area as the Example. Journal of Soil and Water Conservation 17(3), 86-88, 92 (2003) (in Chinese)

6. Bi, R., Wang, B., Wang, J.: Establishment and Application of MAPGIS-based Cultivated Land Fertility Evaluation System. Journal of Shanxi Agricultural University 25(2), 97-101 (2005) (in Chinese)

7. Liu, Y., Wang, J., Liu, J.: Research of County-level Cultivated Land Classification und er Support of Geographical Information System. Journal of Nanjing Agricultural University 24(3), 106-110 (2001) (in Chinese)

8. Niu, Y., Xu, H., Qin, S.: Research of GIS-supported Cultivated Land Fertility Evaluation Method. Journal of Hebei Agricultural University 27(3), 85-88 (2004) (in Chinese) 